\title{
Activated A7nachr Improves Postoperative Cognitive Dysfunction and Intestinal Injury Induced by Cardiopulmonary Bypass in Rats: Inhibition of the Proinflammatory Response Through the Th17 Immune Response
}

\author{
Keyan Chen ${ }^{\mathrm{a}}$ YingJie Sun ${ }^{\mathrm{b}}$ Wanwei Dong ${ }^{\mathrm{a}}$ Tiezheng Zhang ${ }^{\mathrm{b}} \quad$ Nan Zhou $^{\mathrm{b}}$ \\ Weiwei Yuc Yugang Diao ${ }^{b}$ Shanbin Guo ${ }^{d}$ Yue Tianc \\ aDepartment of Laboratory Animal Science, China Medical University, Shenyang North New Area, \\ Shenyang, Liaoning Province, bepartment of Anesthesiology, General Hospital of Shenyang Military \\ Area Command, Shenyang, Liaoning Province, 'Department of Anesthesiology, Shengjing Hospital of \\ China Medical University, Shenyang, Liaoning Province, 'Department of Pharmacy, Shengjing Hospital \\ of China Medical University, Shenyang, Liaoning Province, P.R. China
}

\section{Key Words}

A7nachr • Cardiopulmonary Bypass - Postoperative Cognitive Dysfunction • Intestinal Injury - Th17

\begin{abstract}
Backgrund/Aims: To investigate the effects of activated $\alpha 7$ nicotinic acetylcholine receptor $(\alpha 7 n A C h R)$ on postoperative cognitive dysfunction (POCD) and intestinal injury induced by cardiopulmonary bypass (CPB) and its relationship with the Th17 response in order to provide a theoretical basis for organ protection and targeted drug therapy during the perioperative period. Methods: Sprague-Dawley rat models of CPB were established. Rat intestinal and brain injuries were observed after CPB using hematoxylin and eosin staining. Cell apoptosis was determined using terminal deoxynucleotidyl transferase dUTP nick end labeling. Inflammatory factors and markers of brain injury in rat serum were measured using enzyme-linked immunosorbent assay. The expression levels of Bcl-2, Bax, caspase-3, ZO-1, occludin, AQP4, ROR $\mathrm{T}$, and $\alpha 7 \mathrm{nAchR}$ were examined using western blotting. Transcription factor ROR $\mathrm{T}$ T expression was determined using real-time fluorescent quantitative polymerase chain reaction. Th17 cells in the peripheral blood and spleen were determined using flow cytometry. $\alpha 7 n A c h R$ knockout rats were established. The Th17 response in the peripheral blood and spleen of $\alpha 7 n A c h R$ knockout rats was further verified using flow cytometry. Results: CPB can induce POCD and intestinal injury in rats. $\alpha 7 \mathrm{nAchR}$ activation markedly reduced intestinal injury, POCD, neuronal apoptosis, proinflammatory factor expression, and

Tian Yue

and Shanbin Guo

Department of Anesthesiology, Department of Pharmacy,

Shengjing Hospital of China Medical University, Shenyang, Liaoning Province (P.R. China)

E-Mail tianyue_sj@163.com, shanbinguo@163.com
\end{abstract}


number of $\mathrm{CD} 4^{+} \mathrm{IL}-17^{+}$cells. $\alpha 7 \mathrm{nAchR}$ knockout significantly increased serum D-lactic acid, FABP2, S-100 $\beta$, NSE, TNF- $\alpha$, IL-6, and IL-17 secretion. The number of CD4+IL-17+ cells was also significantly increased. Conclusion: $\alpha 7 \mathrm{nAchR}$ activation markedly ameliorates the intestinal injury and POCD induced by CPB. Inhibition of the Th17 immune response can reduce the proinflammatory response, which could provide a new method for clinical perioperative organ protection and targeted drug therapy.

(C) 2018 The Author(s)

Published by S. Karger AG, Basel

\section{Introduction}

Application of cardiopulmonary bypass (CPB) to open heart surgery has markedly reduced the mortality caused by myocardial infarction, heart failure, and fatal arrhythmias. However, CPB-related complications are still prevalent, such as postoperative cognitive dysfunction (POCD), gastrointestinal injury, and acute lung injury $[1,2]$. CPB causes intestinal mucosal barrier damage, releases toxins and proinflammatory cytokines, and produces a systemic inflammatory response, leading to tissue dysfunction in the brain, lung, liver, kidney, and other organs [3-5]. Previous studies have demonstrated that a systemic inflammatory response, myocardial ischemia-reperfusion, and surgical trauma are the major causes of POCD and intestinal mucosal barrier function impairment after CPB [6-8].

The cholinergic anti-inflammatory pathway was first proposed by Borovikova [9]. It is a neural-immune pathway composed of the vagus nerve, spleen, and acetylcholine (ACh). When noxious stimuli stimulate the body to produce an inflammatory response, signals are introduced to the brain through the vagus nerve. In response, the outgoing vagus nerve releases ACh to the periphery, which binds to $\alpha 7$ nicotinic acetylcholine receptor ( $\alpha 7 \mathrm{nAChR}$ ) on the surface of immunocytes to modulate the inflammatory response [10]. $\alpha 7 \mathrm{nAChR}$ is present in intestinal epithelial cells and intestinal glial cells [11]. Von Boyen et al. [12], using in vitro experiments, verified that a large number of proinflammatory cytokines and the endotoxin-released inflammatory response can activate intestinal epithelial cells and intestinal glial cells and increase the expression of intestinal glial fibrillary acidic protein.

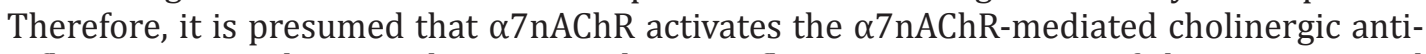
inflammatory pathway and mitigates the proinflammatory response of the intestine and brain induced by CPB.

T helper 17 (Th17) cells are a subset of T helper cells developmentally distinct from Th1 and Th2 lineages. They are related to autoimmune diseases and inflammatory responses and produce interleukin 17 (IL-17). Th17 cells, through the secretion of IL-17, induce collective mobilization, recruitment, and activation of neutrophils and macrophages, mediate inflammatory cell infiltration and tissue damage, and cause the inflammatory response [13, 14]. Retinoid-related orphan receptor gamma t $(\mathrm{ROR} \gamma \mathrm{T})$ is a key transcription factor that regulates the differentiation of Th17 cells and induces initial T cell differentiation into Th17 cells. Liu et al. [15] found that $\alpha 7 \mathrm{nAchR}$ activation by nicotine increased the number of Th17 cells. In addition, $\alpha 7 \mathrm{nAchR}$ suppression by $\alpha$-BTX reduced the number of CD4+IL-17 ${ }^{+} \mathrm{T}$ lymphocytes in the peripheral blood. Finally, activated $\alpha 7 \mathrm{nAchR}$ lessens the Th17 response. In order to provide a theoretical basis for organ protection and targeted drug therapy during the perioperative period, this study explored the mechanism of intestinal tract and brain injury and revealed the relationship between $\alpha 7 \mathrm{nAchR}$ and the Th17 response in a rat model of CPB.

\section{Materials and Methods}

Animals and experimental protocols

Sprague-Dawley rats weighing 260-280 g were provided by the Experimental Animal Department of China Medical University (production license no. SCXK [Liao] 2013-0001, application license no. SYXK [Liao 2013-0007]). The project was approved by the China Medical University Institutional Animal Care and Use 


\section{Cellular Physiology Cell Physiol Biochem 2018;46:1175-1188 \\ and Biochemistry Published online: April 19, $2018 \quad$\begin{tabular}{l|l} 
DOI: 10.1159/000489068 2018 The Author(s). Published by S. Karger AG, Basel \\
www.karger.com/cpb
\end{tabular}}

Chen et al.: Activated A7nachr Improves POCD and Intestinal Injury by Th17 Immune

Response During CPB

Committee (IACUC no. 2016014R). Experimental rats were randomly divided into three groups: the sham surgery group (sham group), CPB model group (CPB group), and PHA568487 (0.8 mg/kg) (an $\alpha 7 \mathrm{nAchR}$ agonist) treatment group (PHA group). The CPB group was subdivided into five subgroups: the $\mathrm{CPB} 0 \mathrm{~h}$ (CPB), CBP 6 h, CPB 12 h, CPB 24 h, and CPB 48 h groups. $\alpha 7 \mathrm{nAchR}$ knockout rats were randomly divided into two groups: $\alpha 7 n$ AchR knockout sham surgery $\left(\alpha 7^{\%}\right)$ and $\alpha 7 n$ AchR knockout CPB model $\left(\alpha 7^{\%}\right.$ CPB) groups. $\alpha 7 \mathrm{nAchR}$ knockout rats were donated by the Key Laboratory of Transgenic Animals, Experimental Animal Division, China Medical University.

\section{Establishment of CPB rat models}

After a 6-h preoperative fast (with water), rats were anesthetized with $2 \%$ sodium pentobarbital and underwent tracheal intubation by using a 16-G trocar. Mechanical ventilation was then performed with an anesthesia machine and ventilator; a 24-G trocar was inserted into the right femoral vein, providing venous access for infusion; a 22-G trocar was inserted into the left femoral artery and connected with a monitor to measure real-time arterial blood pressure. Another 22-G trocar was inserted into the caudal artery and used as a perfusion artery for CPB. An 18-G puncture needle was inserted into the right atrium via the right internal jugular vein as the CPB outflow end. A CPB model without blood preconditioning was established as previously described [16]. The equipment was connected by PVC tube (internal diameter, $1.6 \mathrm{~mm}$ ) and included a venous drainage tube, blood reservoir, arterial infusion tube, filter, and connecting pipe. The circulating prefilled solution comprised $15 \mathrm{~mL}$ : $6 \mathrm{~mL}$ hydroxyethyl starch, $6 \mathrm{~mL}$ lactate Ringer's solution, 1 $\mathrm{mL}$ heparin (250 IU/kg), $1 \mathrm{~mL} 5 \%$ sodium bicarbonate, and $1 \mathrm{~mL} \mathrm{20 \%} \mathrm{mannitol.} \mathrm{When} \mathrm{the} \mathrm{CPB} \mathrm{began,} \mathrm{the}$ mechanical ventilation was terminated and the flow rate was at least $80 \mathrm{~mL} / \mathrm{kg} / \mathrm{min}$. Cycle capacity was added to enhance the flow if the flow rate was lower than 80 . The flow time was $60 \mathrm{~min}$. During the CPB, the oxygen-air mixture (1:4) was maintained at $800 \mathrm{~mL} / \mathrm{min}$ through the membrane lung. Before the CPB was terminated, the mechanical ventilation was resumed and the circulation was gradually stopped by adjusting the inner diameter of the venous outflow end. Subsequently, the right internal jugular vein and caudal artery were ligated and the incision was sutured. If the hemodynamic situation was unstable, appropriate amounts of intravenous adrenaline $(0.1 \mathrm{mg} / \mathrm{kg})$ and dopamine were injected and the speed of rehydration was changed. Hemodynamic stability is considered to be achieved in the CPB model within $6 \mathrm{~h}$ after the end of CPB. After rats resumed spontaneous breathing, tracheal intubation was terminated and rats were observed in the laboratory. Rats in the PHA group were given intraperitoneal injection of PHA568487 (0.8 $\mathrm{mg} / \mathrm{kg}) 3 \mathrm{~h}$ before CPB induction.

\section{Specimen collection and processing}

Blood samples $(1 \mathrm{~mL})$ were taken from the internal jugular vein and the serum was separated by centrifugation for enzyme-linked immunosorbent assay (ELISA). Rat intestinal and brain tissues were fixed in neutral formalin or stored in liquid nitrogen. Blood and spleen tissue were collected for lymphocyte separation.

\section{Morris water maze test}

To evaluate spatial memory and learning abilities, 8 rats were randomly chosen for the Morris water maze test $24 \mathrm{~h}$ after CPB. A platform was placed in the center of the test field. The rat was allowed to locate the platform and land on it within $30 \mathrm{~s}$. If the rat failed to do it within $90 \mathrm{~s}$, it was picked up and placed on the platform. These rats were considered to have a 90-s escape latency. After landing on the platform, each rat was kept on it for $30 \mathrm{~s}$ to strengthen the memory of the platform. The escape latency was recorded and averaged. After the navigation training, the platform was removed. The test session began from the contralateral quadrant of the original platform quadrant with the rat facing the wall of the pool. The time duration in the original platform quadrant and the frequency of crossing were recorded and calculated.

\section{Histopathological changes}

Intestinal and brain tissues were harvested and fixed with neutral formalin. After $48 \mathrm{~h}$, specimens were dehydrated with 70\%, 80\%, 90\%, 95\%, and 100\% ethanol, followed by xylene transparency, and then embedded in paraffin and sliced. Sections were deparaffinized, transferred to xylene, dehydrated with gradient ethanol, stained with hematoxylin for $3 \mathrm{~min}$, differentiated with $0.3 \%$ hydrochloric acid for $30 \mathrm{~s}$, diluted with aqueous ammonia for $1 \mathrm{~min}$, and counterstained with $0.5 \%$ eosin solution for $1 \mathrm{~min}$. 


\section{Cellular Physiology Cell Physiol Biochem 2018;46:1175-1188 \\ and Biochemistry Published onlıne: April19, $2018 \quad \begin{aligned} & \text { DOI: 10.1159/000489068 } 2018 \text { The Author(s). Published by S. Karger AG, Basel } \\ & \text { www.karger.com/cpb }\end{aligned}$}

Chen et al.: Activated A7nachr Improves POCD and Intestinal Injury by Th17 Immune

Response During CPB

Sections were washed with distilled water after each step. After staining, sections were dehydrated, rinsed, permeabilized with xylene, mounted, and the pathological changes in the brain tissue were observed under light microscopy.

Terminal deoxynucleotidyl transferase dUTP nick end labeling (TUNEL) staining

Brain tissue apoptosis was detected according to the instructions of the TUNEL In Situ Cell Death Detection Kit, POD (11684817910, Roche). Brain tissue was dehydrated, embedded, sliced, and incubated with $0.9 \% \mathrm{NaCl}$ for $5 \mathrm{~min}$, then rinsed twice with PBS, mixed with biotinylated nucleotides and terminal deoxynucleotidyl transferase, covered with plastic coverslips, and incubated at $37^{\circ} \mathrm{C}$ for 60 min. After another PBS wash, the brain tissue was blocked with $0.3 \%$ hydrogen peroxide, incubated with horseradish peroxidase-labeled streptavidin at room temperature for $30 \mathrm{~min}$, and then washed, DAB stained, mounted, and observed under a microscope.

\section{ELISA}

Proinflammatory factors such as IL-6 (SEA079Ra, CCC, USA), TNF- $\alpha$ (SEA133Ra, CCC), and IL-17 (SEA063Ra, CCC), intestine injury markers such as D-lactic acid (PAA217Gu01, CCC) and FABP2 (USCN, SEA559Ra), and brain injury markers such as S-100 $\beta$ (SEA567Ra, CCC) and neuron-specific enolase (NSE) (SEA537Ra, CCC) in the plasma of rats were measured by ELISA kits. The optical density (OD) at $450 \mathrm{~nm}$ was measured with a microplate reader. Standard curves were plotted by taking the OD value as the ordinate and the standard sample concentration as the abscissa. The curve equation and $r$ value were calculated. The sample concentration value was measured.

\section{Western blot assay}

The samples were lysed and centrifuged in a pre-chilled tissue lysate at 12, $000 \mathrm{rpm}$ for $30 \mathrm{~min}$. The supernatant of total protein was extracted for sodium dodecyl sulphate-polyacrylamide gel electrophoresis and the protein was semi-dried for membrane transfer. The membranes were blocked for $2 \mathrm{~h}$ and incubated overnight at $4^{\circ} \mathrm{C}$ with antibodies against Bcl-2 (ab59348, Abcam, USA), Bax (ab32503, Abcam), caspase-3 (ab13847, Abcam), ZO-1(ab214228, Abcam), occludin (ab167161, Abcam), AQP4 (ab9512, Abcam), R0R $\gamma$ T (ab207082, Abcam), and $\alpha 7 \mathrm{nAchR}$ (ab24644, Abcam), followed by three washes and incubation with secondary antibody for $1 \mathrm{~h}$. After four washes using TBST, cells were developed with an ECL luminescence kit and gel imaging system and gray values were measured by using Quantity One software.

Quantitative real-time polymerase chain reaction (PCR)

Primers were designed according to the sequences of ROR $\gamma \mathrm{T}$ reported in Genbank and were synthesized by Shanghai Biomedical Biotechnology Co., Ltd. (Shanghai, China). Total RNA in blood and spleen lymphocytes was isolated with TRIzol reagent (15596018, Invitrogen) and reversely transcribed into cDNA (4387406, Invitrogen) in strict accordance with the instructions of the RR820A real-time PCR kit (TAKARA, China). The relative gene expression was analyzed with the $2^{2-\triangle \triangle \mathrm{Ct}}$ method. The primers used for real-time PCR were as follows: ROR $\gamma$ T, forward: AGGTATGACCGATGCTCTTA, reverse, TATTTTCGGATAAGTCTAGG; GAPDH, forward, ATCTTTGGCACTCTCGAAGG; reverse, CGCATTAAGGGTAGGAACAC.

\section{DNA extraction from the tail of $\alpha 7 n A c h R$ knockout rats and PCR}

Primers were designed according to the sequences of $\alpha 7 \mathrm{nAchR}$ reported in Genbank, and were synthesized by Shanghai Biomedical Biotechnology Co., Ltd. DNA was isolated with QIAamp Fast DNA Tissue Kit (51404, Qiagen) and PCR was used for the detection. The reaction system was as follows: DNA template $2 \mu \mathrm{L}$, wild-type primer $1 \mu \mathrm{L}$, mutant primer $1 \mu \mathrm{L}$, universal primer $1 \mu \mathrm{L}$, Taq mix $12.5 \mu \mathrm{L}$, and $\mathrm{ddH}_{2} \mathrm{O} 7.5 \mu \mathrm{L}$. The reaction conditions were as follows: pre-denaturation at $95^{\circ} \mathrm{C}$ for $5 \mathrm{~min} ; 35$ cycles of denaturation at $95^{\circ} \mathrm{C}$ for $30 \mathrm{~s}$, annealing at $57^{\circ} \mathrm{C}$ for $30 \mathrm{~s}$, and elongation at $72^{\circ} \mathrm{C}$ for $1 \mathrm{~min}$; and elongation for $5 \mathrm{~min}$. Afterward, the genotype was identified using agarose gel electrophoresis. The primers used for the PCR were as follows: wild-type, AGGTATGACCGATGCTCTTA; mutant, TATTTTCGGATAAGTCTAGG; universal, ATCTTTGGCACTCTCGAAGG.

\section{Flow cytometry}

The rat spleen and peripheral blood ( $5 \mathrm{~mL}$ ) were obtained. The spleen was triturated in RPMI-1640 medium. Splenic suspensions and blood were placed in a 15-mL centrifuge tube, washed with PBS, and centrifuged. After removal of the supernatant, an equal volume of erythrocyte lysate was added on ice for 
$5 \mathrm{~min}$, followed by centrifugation. The supernatant was discarded. PBS ( $5 \mathrm{~mL}$ ) was added and the sample was mixed and centrifuged. After removal of the supernatant, all samples were resuspended with RPMI1640 medium. Cells at $1 \times 10^{6}$ were seeded into 6-well plates after the addition of RPMI-1640 medium to a total volume of $1 \mathrm{~mL}$. The cells in each well were incubated with PMA (Sigma), ionomycin (Sigma), and Brefeldin A (Sigma) at final concentrations of $10 \mathrm{ng} / \mathrm{mL}, 0.5 \mu \mathrm{g} / \mathrm{mL}$, and $1 \mu \mathrm{L} / \mathrm{mL}$, respectively, and then incubated at $37^{\circ} \mathrm{C}$ in $5 \% \mathrm{CO}_{2}$ for $5 \mathrm{~h}$. After stimulation, the cells were collected in an Eppendorf tube and centrifuged. After removal of the supernatant, the cells were washed with PBS $1 \mathrm{~mL}$, mixed with PBS 100 $\mu \mathrm{L}$, and incubated with FITC-anti-CD4 $4^{+}(554843, \mathrm{BD}, \mathrm{USA})$ at $4^{\circ} \mathrm{C}$ in the dark for $30 \mathrm{~min}$. The cells were then washed twice with cell staining buffer, uniformly mixed with $500 \mu \mathrm{L}$ fixation/permeabilization solution, and incubated at $4^{\circ} \mathrm{C}$ in the dark for $30 \mathrm{~min}$. They were next washed with PBS $1 \mathrm{~mL}$, mixed with PBS $100 \mu \mathrm{L}$, and incubated with PE-anti-IL- $17^{+}\left(12-7177-81\right.$, eBioscience, USA) at $4^{\circ} \mathrm{C}$ in the dark for $50 \mathrm{~min}$. Subsequently, they were washed with $1 \times$ BD perm/wash buffer, resuspended with $300 \mu \mathrm{L}$ PBS, and analyzed using flow cytometry. Results were analyzed using FlowJo software.

\section{Statistical analysis}

Data were analyzed using SPSS 19.0 statistical software. Measurement data are expressed as mean \pm standard deviation. Data between groups were compared using an independent samples $t$-test. Data among groups were compared using one-way analysis of variance with $\mathrm{S}-\mathrm{N}-\mathrm{K}$ test analysis. A value of $P<0.05$ was regarded as significant.

\section{Results}

\section{Establishment of the CPB rat model and assessment of hemodynamic changes}

Compared with the before bypass period $\left(\mathrm{T}_{0}\right)$, the mean arterial pressure (MAP) significantly decreased in each group during the bypass $\left(\mathrm{T}_{1}\right)(P<0.05$; Fig. 1$)$; the MAP was restored $2 \mathrm{~h}$ after the bypass (T2), and no significant difference was detected $(P>$ $0.05)$. Hemoglobin $(\mathrm{Hb})$ significantly diminished after the bypass $\left(\mathrm{T}_{1}-\mathrm{T}_{3}\right)(P<0.05)$. Rectal temperature, $\mathrm{pH}$ value, partial pressure of arterial carbon dioxide $\left(\mathrm{PaCO}_{2}\right)$, and partial pressure of oxygen $\left(\mathrm{PaO}_{2}\right)$ were stable during the $\mathrm{CPB}$, and no significant difference was detected compared with the before bypass period $\left(\mathrm{T}_{0}\right)(P>0.05)$. These results indicated that our CPB model was stable (Table 1).

\section{$C P B$ induces intestinal injury and POCD in rats}

Confirming the intestinal injury and brain injury induced by $\mathrm{CPB}$, there was a serum D-lactic acid and FABP2 increase at $6 \mathrm{~h}$ after CPB $(P=0.016$ vs before bypass, $P=0.031$ vs before bypass, respectively)

(Fig. 2A). D-lactic acid and FABP2 secretion peaked at $12 \mathrm{~h}$ after $\mathrm{CPB}(P<0.001$ vs before bypass). ZO-1 and occludin protein expression decreased at $6 \mathrm{~h}$ after CPB $(P=0.024$ vs before bypass, $P=0.018$ vs before bypass, respectively), and AQP4 protein expression increased at $6 \mathrm{~h}$ after $\mathrm{CPB}$ $(P=0.003$ vs before bypass) (Fig. 2B and C). These data suggested that intestinal injury occurred at $6 \mathrm{~h}$ after CPB. Serum S-100 $\beta$ and NSE expression significantly

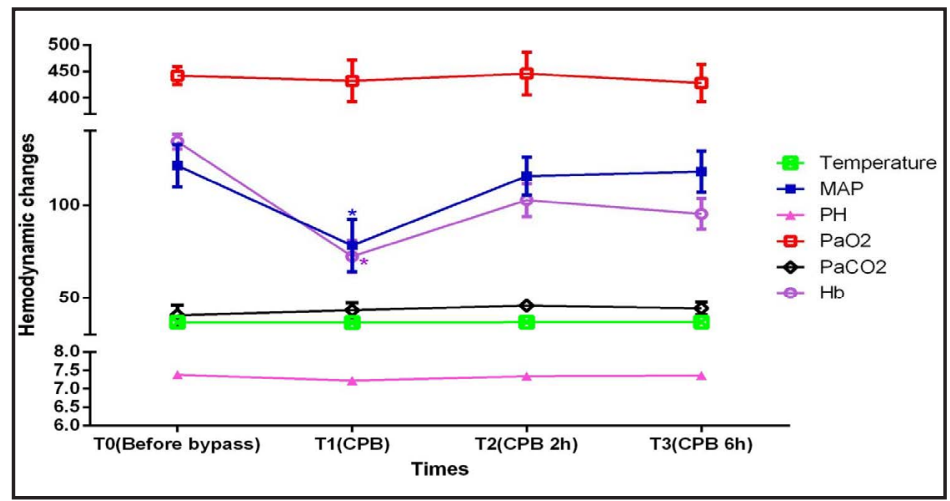

Fig. 1. Establishment of the $C P B$ rat. Hemodynamic changes were measured at different time points after injection of $3 \mathrm{mg} / 300 \mathrm{~g}$ of heparin anticoagulation into the rat tail artery and connection of the Multi-function monitor. Data were collected before the bypass, at CPB, CPB 2 h, and CPB 6 h. Compared with before bypass, ${ }^{*} \mathrm{P}<0.05$. 
Response During CPB

increased at $24 \mathrm{~h}$ after $\mathrm{CPB}$ $(P<0.001$ vs before bypass) (Fig. 2D). Expression of the apoptotic proteins Bax and caspase- 3 was significantly increased $(P<0.001$ vs before bypass) (Fig. 2E and F), whereas anti-apoptotic protein Bcl-2 expression was significantly reduced (Fig. 2E and F). This is consistent with the clinical cognitive impairment seen 24 to $48 \mathrm{~h}$ after cardiac surgery in most patients undergoing CPB [17-19].

\section{Activated $\quad \alpha 7 n$ AchR attenuates the intestinal injury and $P O C D$ induced by CPB in rats}

To verify that activated $\alpha 7 \mathrm{nAchR}$ can attenuate the intestinal injury and POCD induced by $\mathrm{CPB}, 24 \mathrm{~h}$ after CPB was considered the time of $\alpha 7 \mathrm{nAch}$ activation. Hematoxylin and eosin staining revealed that, in the sham group, the intestinal mucosa was normal and the villi were arranged regularly and the neurons were arranged regularly and closely, with clear cell boundaries and without abnormal structures (Fig. $3 \mathrm{~A})$. In the CPB group, the villi of the intestinal mucosa were shortened. The intestinal mucosa was bleeding and edematous and infiltrated by a number of inflammatory cells, and the intestinal epithelial cells were denatured and necrotic; additionally, the arrangement of neuron cells was scattered, and the cells were sparse and unevenly distributed (Fig. 3A). Neuronal apoptosis was significantly increased
Table 1. Hemodynamic changes. Compared with $\mathrm{T}_{0},{ }^{*} \mathrm{P}<0.05$

\begin{tabular}{lllll}
\hline & $\mathrm{T}_{0}$ (before bypass) & $\mathrm{T}_{1}(\mathrm{CPB})$ & $\mathrm{T}_{2}(\mathrm{CPB} 2 \mathrm{~h})$ & $\mathrm{T}_{3}(\mathrm{CPB} 6 \mathrm{~h})$ \\
\hline $\mathrm{T}\left({ }^{\circ} \mathrm{C}\right)$ & $36.74 \pm 0.52$ & $36.64 \pm 1.09$ & $36.80 \pm 2.2$ & $36.82 \pm 1.9$ \\
$\mathrm{MAP}(\mathrm{mmHg})$ & $121.32 \pm 11.31$ & $78.42 \pm 14.11^{*}$ & $115.68 \pm 10.12$ & $118.08 \pm 11.13$ \\
$\mathrm{pH}$ & $7.38 \pm 0.04$ & $7.22 \pm 0.1$ & $7.34 \pm 0.06$ & $7.36 \pm 0.05$ \\
$\mathrm{PaO}_{2}(\mathrm{mmHg})$ & $442 \pm 17.22$ & $432 \pm 39.77$ & $446 \pm 40.30$ & $428 \pm 35.89$ \\
$\mathrm{PaCO}_{2}(\mathrm{mmHg})$ & $40.45 \pm 5.53$ & $43.22 \pm 3.93$ & $45.78 \pm 2.56$ & $44.20 \pm 3.44$ \\
$\mathrm{Hb}(\mathrm{g} / \mathrm{L})$ & $134.2 \pm 4$ & $72.6 \pm 8.6^{*}$ & $102.8 \pm 8.8^{*}$ & $95.4 \pm 8.3^{*}$ \\
& & & &
\end{tabular}

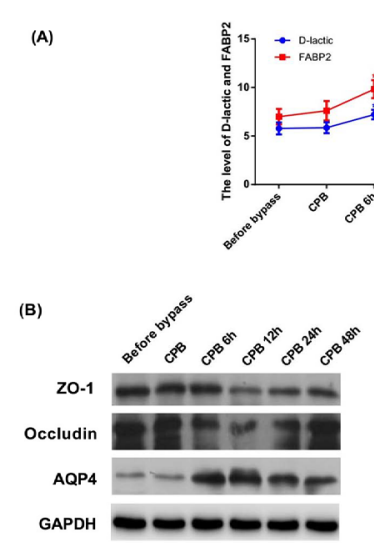

(D)
(C) $\quad$ zo-1

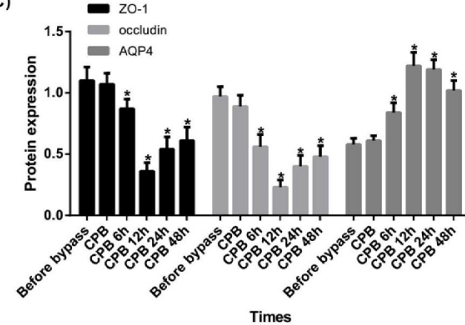

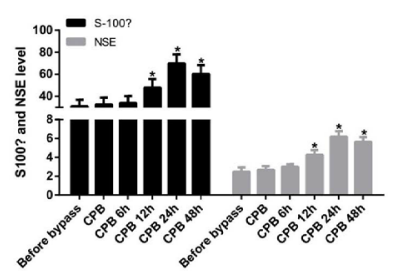
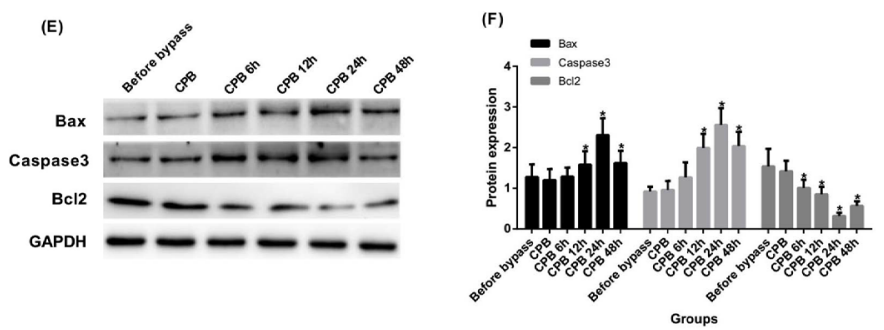

Fig. 2. $C P B$ induces intestinal injury and POCD in rats. A: Blood samples were collected at different time points, and the serum was isolated. ELISA was used to determine D-lactic and FABP2 levels at different time points. B and C: After collection of rat intestinal tissue and total protein isolation, a western blot assay was used to determine Z0-1, occludin, and AQP4 protein expression. D: Serum was isolated at different time points and ELISA was used to determine S100 $\beta$ and NSE levels. E and F: After collection of rat intestinal tissue and total protein isolation, a western blot assay was used to determine Bax, caspase-3, and Bcl-2 protein expression. There was still high expression of D-lactic, FABP2, and AQP4 at CPB $24 \mathrm{~h}$. Because the expression of S100 $\beta$, NSE, Bax, and caspase- 3 was significantly increased, we choose $24 \mathrm{~h}$ as the CPB group. Compared with before bypass, ${ }^{*} \mathrm{P}<0.05$. 


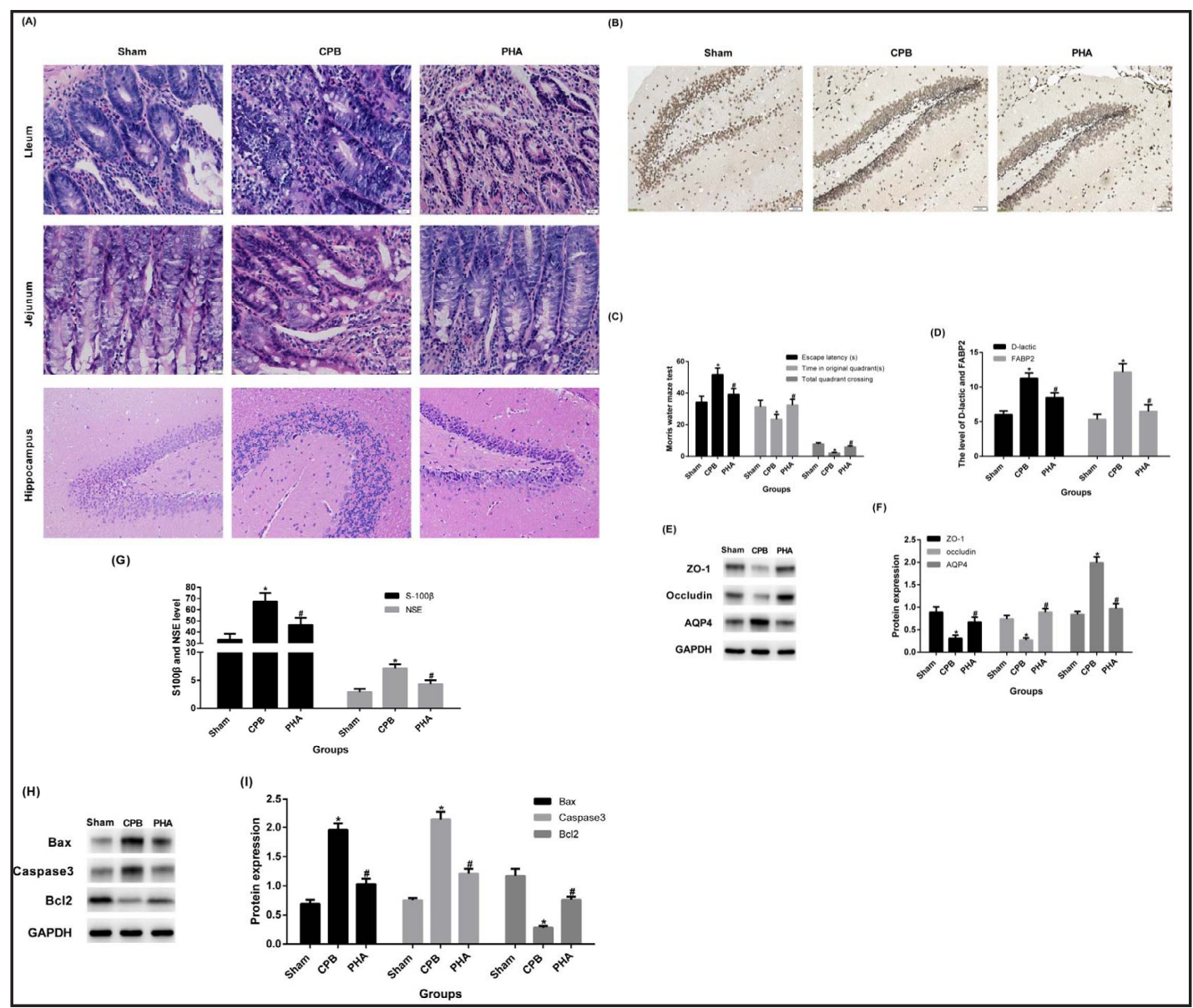

Fig. 3. Activated $\alpha 7 \mathrm{nAchR}$ attenuates the intestinal injury and POCD induced by CPB. We administered an intraperitoneal injection of PHA568487 $(0.8 \mathrm{mg} / \mathrm{kg})$ to rats. A: The intestinal tissue from the sham, CPB, and PHA groups was collected. The tissue was fixed in 10\% formaldehyde, embedded in paraffin, and sectioned. Hematoxylin and eosin staining was used to observe the pathological changes. B: TUNEL staining was used to determine hippocampal tissue apoptosis. C: The Morris water maze test was used to determine the rats' learning and memory dysfunction. D: ELISA was used to determine D-lactic and FABP2 levels in the serum. E and F: Western blot assay was used to determine ZO-1, occludin, and AQP4 protein expression. G: ELISA was applied to determine S100 $\beta$ and NSE levels. $\mathrm{H}$ and I: Western blot assay was used to determine Bax, caspase- 3 , and Bcl-2 protein expression. Compared with the sham group, ${ }^{*} \mathrm{P}<0.05$; compared with the CPB group, ${ }^{\text {}} \mathrm{P}<0.05$.

on TUNEL staining (Fig. 3B). The PHA group showed mild expansion of the intestinal mucosal gland, mild degeneration of intestinal epithelial cells, and a small amount of inflammatory cell release; the neurons were arranged neatly and the cell band was incomplete (Fig. 3A), and neuronal apoptosis was significantly decreased (Fig. 3B).

To determine the cognitive impairment induced by $\mathrm{CPB}$, we conducted the Morris water maze test. Data showed that the escape latency was significantly prolonged in the CPB group while the time spent in the original platform quadrant was shortened and the frequency of crossing was decreased (Fig. 3C), indicating that the spatial memory was impaired after CPB. After $\alpha 7 \mathrm{nAchR}$ activation, serum D-lactic acid and FABP2 secretion was significantly diminished ( $P<0.001$ vs CPB group) (Fig. 3D). ZO-1 and occludin protein expression was significantly increased and AQP4 protein expression was significantly decreased $(P<0.001$ vs CPB group) (Fig. 3E and F). S-100 $\beta$ and NSE expression was significantly diminished ( $P$ $<0.001$ vs CPB group) (Fig. 3G). Bax and caspase-3 protein expression was significantly decreased $(P<0.001$ vs CPB group), whereas Bcl- 2 expression was significantly increased $(P$ 
$<0.001$ vs CPB group) (Fig. $3 \mathrm{H}$ and I). The escape latency was significantly shortened, the time spent at the original platform quadrant was prolonged, and the frequency of crossing was increased $(P$ $<0.001$ vs CPB group) (Fig. $3 C)$. These data suggested that $\alpha 7 \mathrm{nAchR}$ activation could markedly suppress the intestinal injury and POCD induced by CPB.

Activated $\alpha 7 n A c h R$ inhibits the proinflammatory response in rats undergoing $C P B$

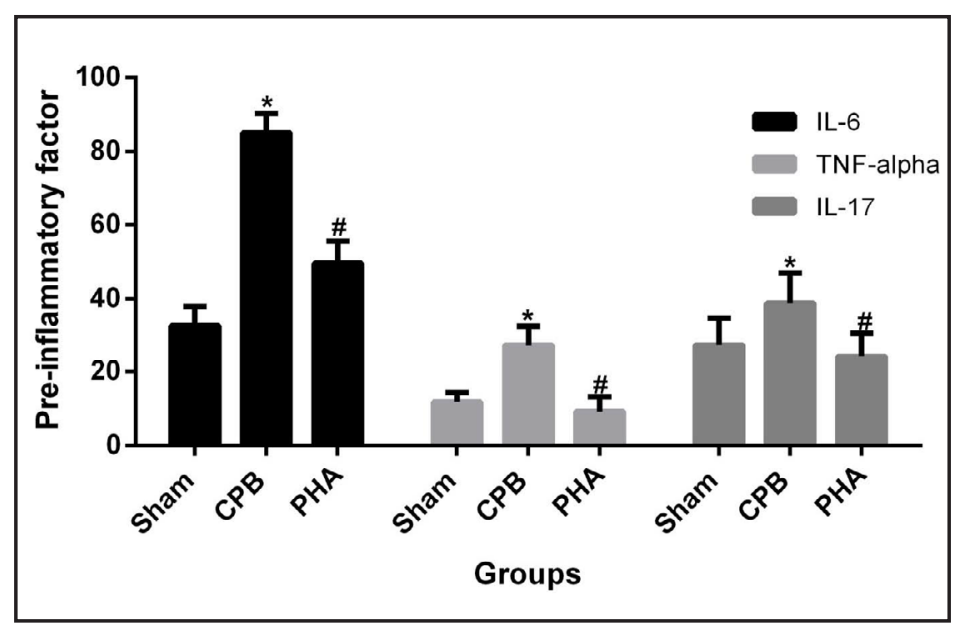

Fig. 4. Activated $\alpha 7 n A c h R$ inhibits the proinflammatory response. After $\alpha 7 \mathrm{nAchR}$ activation, the levels of IL-6, TNF- $\alpha$, and IL-17a were significantly decreased. Compared with the sham group, ${ }^{*} \mathrm{P}<0.05$; compared with the CPB group, ${ }^{\#} \mathrm{P}<0.05$.

To further verify that activated $\alpha 7 \mathrm{nAchR}$ inhibits the proinflammatory response after $\mathrm{CPB}$, ELISA was used to determine the levels of the proinflammatory cytokines TNF- $\alpha$, IL-6, and IL-17 in rat peripheral blood. The ELISA showed that TNF- $\alpha$, IL-6, and IL-17 expression was significantly increased in the CPB group $(P<$ 0.001 vs sham group) (Fig. 4). In contrast, TNF- $\alpha$, IL-6, and IL-17 expression was significantly decreased in the peripheral blood of rats in the PHA group ( $P<0.001$ vs CPB group) (Fig. 4).

Th17 is downregulated in the peripheral blood and spleen of rats undergoing CPB after $\alpha 7 n$ AchR activation

To verify the changes in Th17 cells after $\alpha 7 \mathrm{nAchR}$ activation, flow cytometry was used to detect the number of CD4+IL-17 $7^{+}$lymphocytes in the peripheral blood and spleen. Flow cytometry results showed that the number of CD4+IL-17+ lymphocytes was significantly increased in the CPB group ( $P<0.001$ vs sham group) (Fig. 5A-C). After $\alpha 7 \mathrm{nAchR}$ activation, the number of $\mathrm{CD} 4^{+} \mathrm{IL}-17^{+}$lymphocytes was significantly reduced in the blood and spleen $(P<0.001$ vs CPB group) (Fig. 5A-C). Quantitative real-time PCR and western blot assay results showed that the Th17 cell transcription factor ROR $\gamma \mathrm{T}$ was expressed in the blood and spleen. Data suggested that ROR $\gamma$ T mRNA expression was significantly increased in the CPB group ( $P=0.002$ vs sham group). After $\alpha 7 \mathrm{nAchR}$ activation, ROR $\gamma \mathrm{T}$ mRNA expression was significantly decreased ( $P=0.003$ vs CPB group) (Fig. 5D). Western blotting results were consistent with those of quantitative real-time PCR (Fig. 5E and F). These results indicated that activated $\alpha 7 \mathrm{nAchR}$ improved the proinflammatory response in the intestines and brains of rats undergoing $\mathrm{CPB}$, possibly through the Th17 immune response.

\section{Identification of the genotype in $\alpha 7 n A c h R$ knockout rats}

PCR amplification of target DNA demonstrated that the electrophoresis band of wildtype rats was located at $324 \mathrm{bp}$ (Fig. 6A). The bands of heterozygotes were at $237 \mathrm{bp}$ and $324 \mathrm{bp}$, whereas the band of homozygotes was at $237 \mathrm{bp}$. The proportion of homozygous rats was $30 \%$. To further verify the reliability of the PCR results, western blotting was used to determine $\alpha 7 \mathrm{nAchR}$ protein expression (Fig. 6B). $\alpha 7 \mathrm{nAchR}$ protein expression was not detectable in the tail of homozygous rats but could be detected in wild-type rats. These findings were consistent with the PCR results.

$\alpha 7 n$ AchR deficiency aggravates the POCD and proinflammatory response induced by CPB

To further confirm the relationship between $\alpha 7 \mathrm{nAchR}$ and the proinflammatory response after intestinal injury and brain injury in rats, we established $\alpha 7 \mathrm{nAchR}^{-/-} \mathrm{CPB}$ rat models. 
These animals showed significantly increased D-lactic acid and FABP2 expression $(P<0.001$ vs $\alpha 7^{\%}$ sham group) (Fig. 7A). S-100 $\beta$ and NSE levels were also significantly increased $(P<0.001$ vs $\alpha 7 \%$ sham group) (Fig. 7B). The escape latency in the CPB group was significantly prolonged, whereas the time spent in the original platform quadrant was shortened, and the frequency of crossing was decreased $\left(P<0.001\right.$ vs $\alpha 7^{\%}$ sham group) (Fig. 7C). TNF- $\alpha$, IL-6, and IL-17 levels were significantly increased $\left(P<0.001\right.$ vs $\alpha 7^{\%}$ sham group) (Fig. 7D). These results suggested that, after $\alpha 7 \mathrm{nAchR}$ knockout, the intestinal injury and POCD induced by CPB were aggravated, promoting the proinflammatory response induced by CPB.

Th17 responses in the peripheral blood and spleen of $\alpha 7 n A c h R$ knockout rats undergoing $C P B$

To further verify the relationship between $\alpha 7 \mathrm{nAchR}$ and the Th17 immune response, we found that, after $\alpha 7 n$ AchR knock-

Fig. 6. Genotype identification of $\alpha 7 \mathrm{nAchR}$ knockout rats. PCR and western blot assay were used to determine $\alpha 7 \mathrm{nAchR}$ expression. The electrophoresis band of wild-type rats was located at $324 \mathrm{bp}$, the bands of heterozygotes were located at $237 \mathrm{bp}$ and $324 \mathrm{bp}$, and the band of homozygotes was located at 237 bp. A: PCR. B: Western blot assay.

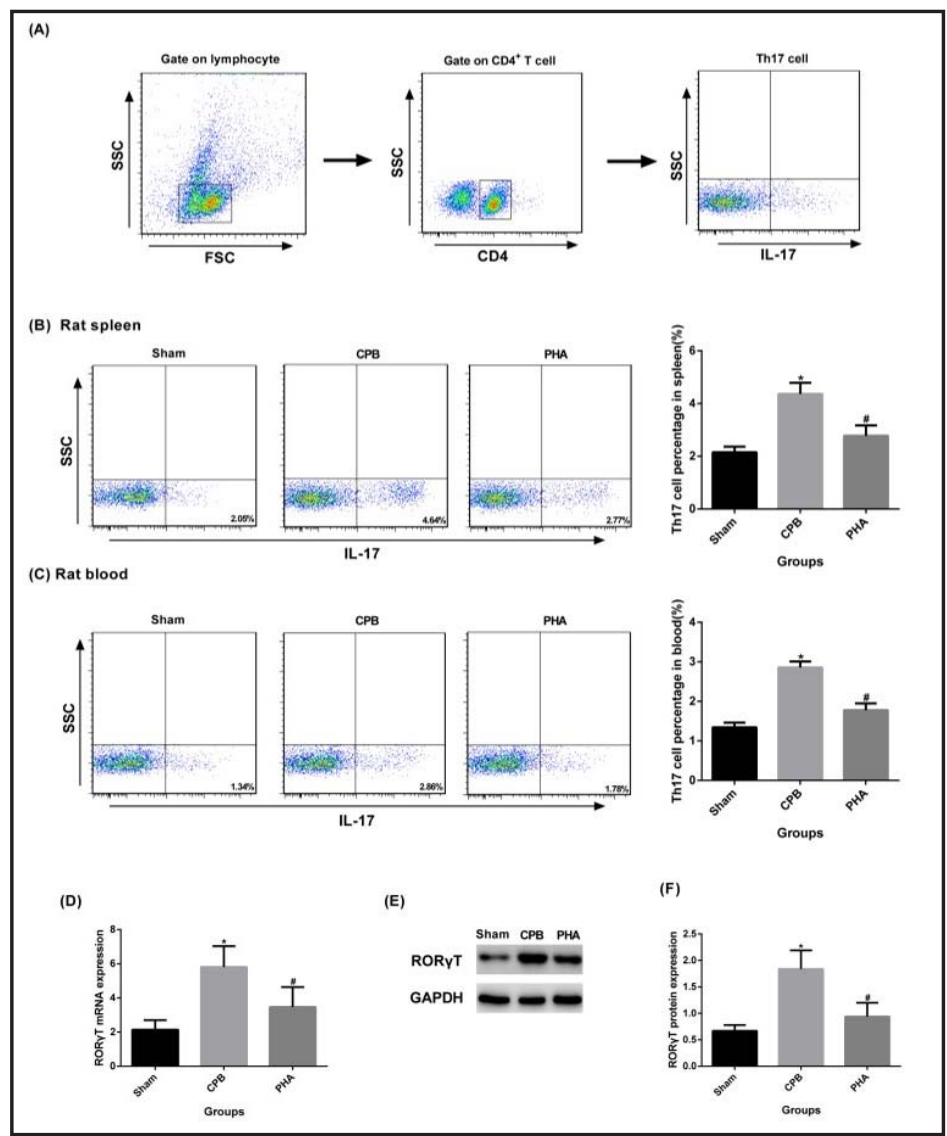

Fig. 5. Th17 is downregulated in the peripheral blood and spleen of rats undergoing $\mathrm{CPB}$ after $\alpha 7 \mathrm{nAch}$ activation. A: The peripheral blood and spleen were collected from the sham, CPB, and PHA groups. PBMCs were isolated. Flow cytometry was used to determine the percentage of $\mathrm{CD} 4^{+} \mathrm{IL}^{-17^{+}}$(Th17) cells. Different cell subsets were distinguished according to different cell labels. B: The percentage of CD4+IL-17+ cells in rat spleen. C: The percentage of $\mathrm{CD}^{+} \mathrm{IL}^{-17^{+}}$cells in rat blood. D: PBMCs were isolated from the peripheral blood and spleen. Total RNA was isolated and cDNA was synthesized by reverse transcription. qRTPCR was used to determine the expression of the Th17 cell transcription factor ROR $\gamma$ T mRNA. E and F: Western blotting was used to determine ROR $\gamma \mathrm{T}$ protein expression. Compared with the sham group, ${ }^{*} \mathrm{P}<0.05$; compared with the CPB group, ${ }^{\#} \mathrm{P}<0.05$.

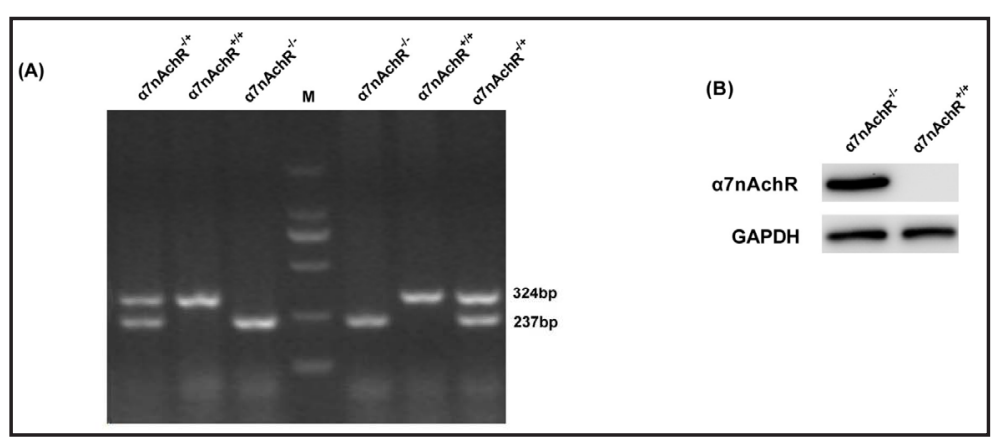


(A)

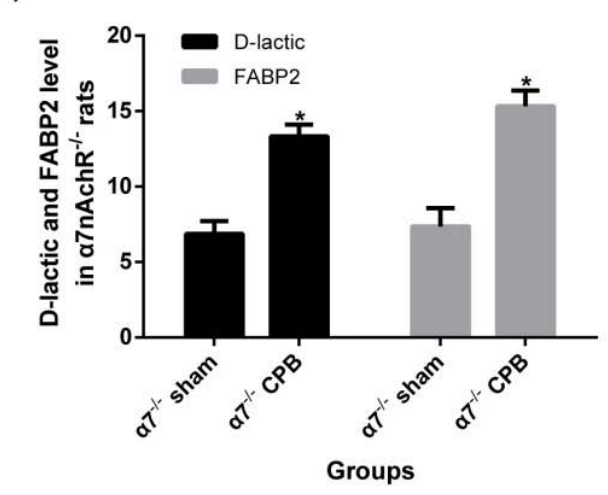

(C)

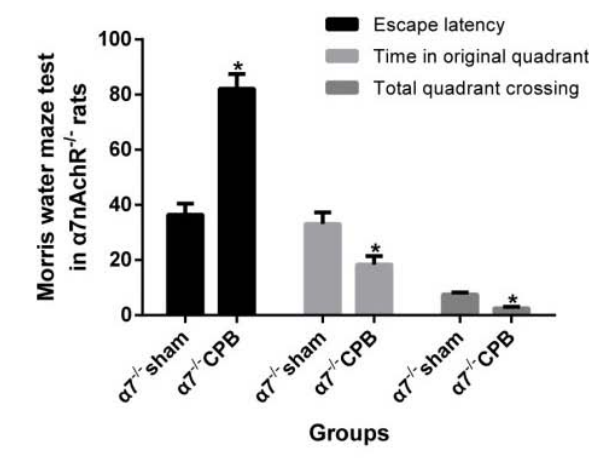

(B)

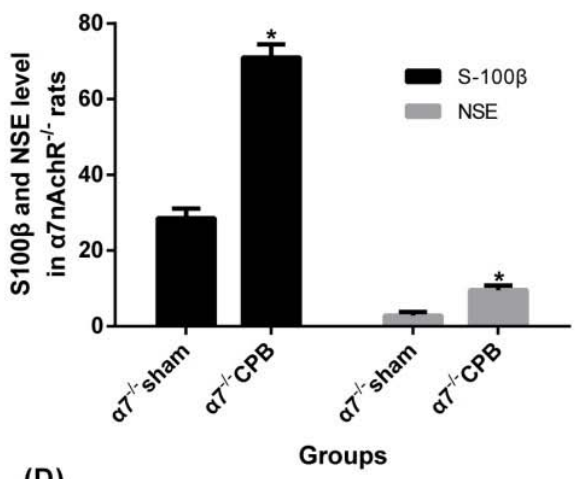

(D)

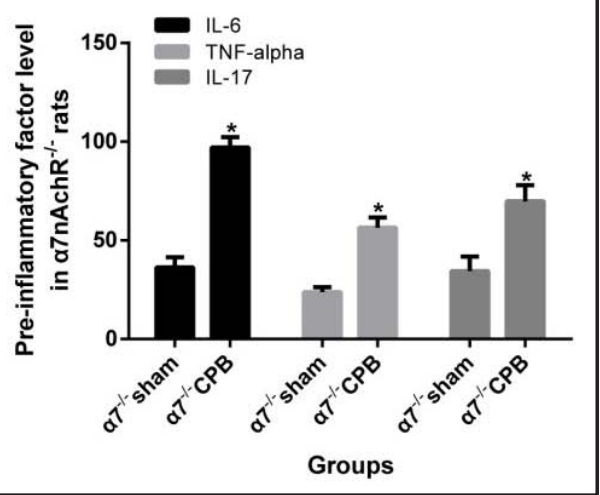

Fig. 7. $\alpha 7 n A c h R$ deficiency aggravates POCD and the proinflammatory response. An $\alpha 7 n A c h R$ knockout CPB model was established. A and B: Serum was collected and ELISA was used to determine D-lactic, FABP2, S100 $\beta$, and NSE levels. C: The Morris water maze test was used to determine any learning and memory dysfunctions. D: ELISA was used to determine the proinflammatory level. Data were collected from the $\alpha 7 \mathrm{nAchR}^{-/}$group and $\alpha 7 \mathrm{nAchR}{ }^{-/}$CPB groups. Compared with the $\alpha 7 \mathrm{nAchR}^{-1}$ sham group, ${ }^{*} \mathrm{P}<0.05$; compared with the $\alpha 7 \mathrm{nAch} \mathrm{R}^{-1-} \mathrm{CPB}$ group, ${ }^{\#} \mathrm{P}<0.05$.

out, the number of $\mathrm{CD} 4^{+} \mathrm{IL}-17^{+}$cells was significantly increased in the CPB group in both the blood and spleen ( $P<0.001$ vs $\alpha 7 \%$ sham group) (Fig. 8A and B). Quantitative real-time PCR and western blot assay results showed that ROR $\gamma \mathrm{T}$ was expressed in the blood and spleen. Data suggested that after $\alpha 7 \mathrm{nAchR}$ knockout, ROR $\gamma \mathrm{T}$ expression was significantly increased in the CPB group ( $P<0.001$ vs $\alpha 7 \%$ sham group) (Fig. 8C-E). These findings further indicated that $\alpha 7 \mathrm{nAchR}$ suppressed the proinflammatory response through the Th17 response and improved the intestinal injury and POCD induced by CPB in rats.

\section{Discussion}

This study established a CPB model and observed the effects of activated $\alpha 7 \mathrm{nAchR}$ and the Th17 response on CPB-induced intestinal injury and POCD. The results from pathological observation of the intestine and brain and detection of proinflammatory factor and Th17 cells revealed that activated $\alpha 7 \mathrm{nAchR}$ mitigated CPB-induced intestinal injury and POCD and inhibited the secretion of proinflammatory factor through the Th17 response. These results provide a theoretical basis for organ protection and targeted drug therapy for CPB-induced injuries during the perioperative period.

Since the 1950s, CPB has been extensively used in clinics and has become an important means of performing open heart surgery. Despite the continuous improvement in different cardiac surgical techniques, the incidence of postoperative complications remains high. Such 
Fig. 8. $\alpha 7 n A c h R$ deficiency aggravates Th17 responses. A and B: Flow cytometry was used to determine the percentage of $\mathrm{CD} 4^{+} \mathrm{IL}-17^{+}$cells. C: qRT-PCR was used to determine the mRNA expression of the Th17 cell transcription factor ROR $\gamma$ T. D: Western blotting assay was used to determine ROR $\gamma \mathrm{T}$ protein expression. Data were collected from the $\alpha 7 \mathrm{nAchR}^{-1-}$ sham and $\alpha 7 \mathrm{nAchR}^{\circ-}$ CPB groups. Compared with the $\alpha 7 \mathrm{nAchR}^{\%-}$ sham group, $* \mathrm{P}<0.05 ; \quad$ compared with the $\alpha 7 \mathrm{nAchR}^{-/-} \mathrm{CPB}$ group, ${ }^{\mathrm{P}}<0.05$.

(A) Rat spleen
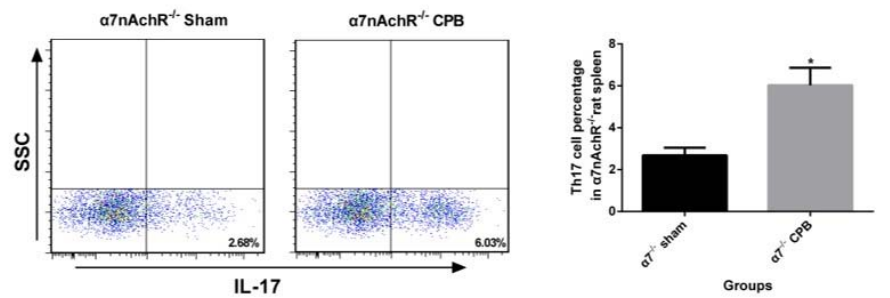

(B) Rat blood
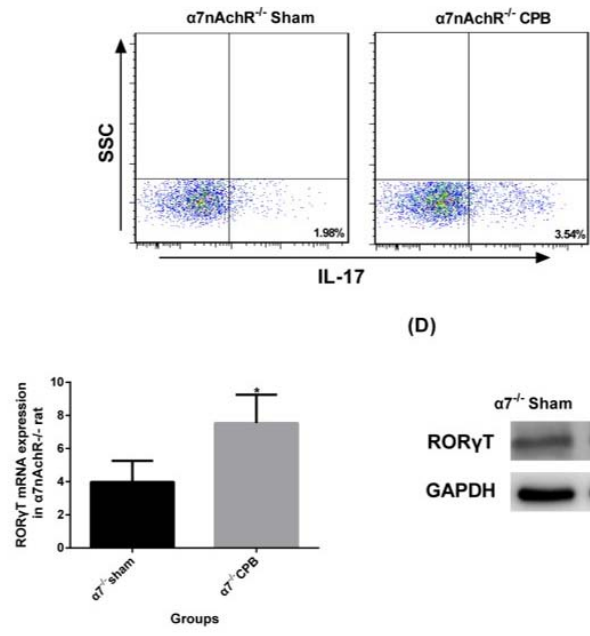

(D)

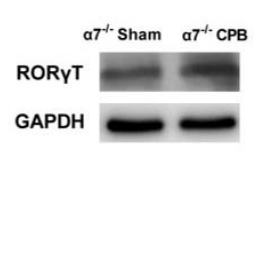

(E)

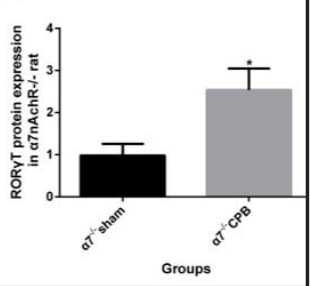

complications, which include POCD [19], acute lung injury [20], kidney injury [21], and intestinal injury [22], have become an important obstacle to the development of cardiac surgery. In this study, 6\% hydroxyethyl starch was injected into Sprague-Dawley rats through the right venous drainage and right femoral artery fusion to establish a CPB model. We found that $6 \mathrm{~h}$ after $\mathrm{CPB}$, serum D-lactic acid and FABP2 secretion began to increase, ZO-1 and occludin expression began to decrease, AQP4 expression increased, and intestinal injury appeared. At $24 \mathrm{~h}$ after CPB, S- $100 \beta$ and NSE secretion was noticeably increased and apoptotic protein expression markedly increased. This is consistent with the POCD induced by CPB in most patients 24-48 $\mathrm{h}$ after cardiac surgery [17-19].

$\alpha 7 \mathrm{nAChR}$ is expressed on the surface of various cells, including lymphocytes, macrophages, dendritic cells, intestinal epithelial cells, and lung epithelial cells [23]. In particular, $\alpha 7 \mathrm{nAChR}$ on macrophages plays a central role in the cholinergic anti-inflammatory pathway. This pathway regulates the immune system through the reticuloendothelial system [24] by inhibiting inflammation through reticuloendothelial system-mediated release of acetylcholine from the appropriate organs. These organs include the lung, spleen, liver, kidney, and gastrointestinal tract. Acetylcholine interacts with $\alpha 7 \mathrm{nAChR}$ on the surface of macrophages and other immune cells and inhibits proinflammatory cytokine release and reduces tissue damage through different pathways. Acetylcholine can significantly reduce the release of TNF- $\alpha$, IL-1b, IL-6, and IL-18 from cultured human macrophages stimulated by LPS [25]. Nevertheless, this effect of acetylcholine disappears in $\alpha 7 \mathrm{nAChR}$ knockout rats [26]. $\alpha 7 \mathrm{nAChR}$ activation inhibits the expression of the NF-kB transcription factor and Toll-like receptor- 4 by modulating the cascade signal transduction chains in monocytes and macrophages, thereby suppressing proinflammatory cytokine transcription. Activated $\alpha 7 \mathrm{nAChR}$ can also increase the levels of Jak2 to form a dimeric complex. This complex can initiate signaling pathway regulated by signal transducer and activator of transcription 3 (STAT3). This pathway can inhibit the binding of NF-kB to DNA and enhance the inhibitory ability of cytokine signaling 3 (SOCS3) on the inflammatory response [27]. Our results confirmed that after $\alpha 7 \mathrm{nAChR}$ was activated by PHA568487, the secretion of serum 
D-lactic acid, FABP2, S-100 $\beta$, and NSE was noticeably reduced in rats undergoing CPB. In addition, TNF- $\alpha$, IL- 6 , and IL-17 secretion was diminished, ZO-1 and occludin expression was increased, and AQP4 protein expression in the intestine was decreased. The escape latency was significantly shortened, the time spent at the original platform quadrant was prolonged, and the frequency of crossing was increased on the Morris water maze test. Bax and caspase- 3 expression was reduced, but Bcl-2 expression was increased. These findings indicated that activated $\alpha 7 \mathrm{nAChR}$ suppressed the proinflammatory response induced by the intestinal injury and the POCD induced by CPB in rats. After $\alpha 7 \mathrm{nAChR}$ knockout, serum TNF- $\alpha$, IL- 6 , and IL-17 secretion significantly increased in rats undergoing CPB. These data further proved that $\alpha 7 \mathrm{nAChR}$ improved the intestinal injury and POCD and inhibited the proinflammatory response in rats undergoing CPB.

Th17 cells, as an independent new subgroup of T helper cells, have unique characteristics in terms of self differentiation, development, and maintenance. Just as T-bet controls Th1 differentiation and GATA-3 controls Th2 differentiation, the differentiation of Th17 cells is controlled by its transcription factor ROR $\gamma \mathrm{T}$ [28]. IL-17 is a major cytokine secreted by Th17 cells that can induce the expression of the inflammatory cytokine IL-6, reactive proteins, G-CSF, and prostaglandin E2 [29]. IL-17 has a synergistic relationship with inflammatory factor TNF- $\alpha$ and amplifies its proinflammatory effect [30]. IL-17 can recruit neutrophils, promote various cells to release inflammatory factor, induce airway mucus glands to secrete mucus, and increase airway hyperresponsiveness, which play an important role in the process of airway remodeling in asthma [31]. Our results demonstrated that the number of Th17 cells clearly increased in the spleen and peripheral blood of rats undergoing CPB. The number of Th17 cells decreased after $\alpha 7 n A C h R$ activation and markedly diminished after $\alpha 7 \mathrm{nAChR}$ knockout in the spleen and peripheral blood of rats undergoing CPB. These results suggested that $\alpha 7 \mathrm{nAChR}$ suppressed the proinflammatory response and improved intestinal and brain injuries through the Th17 response.

\section{Conclusion}

In summary, $\alpha 7 \mathrm{nAChR}$ activation clearly improves the intestinal injuries and POCD induced by CPB. It is likely that $\alpha 7 \mathrm{nAChR}$ activation lessens the proinflammatory response by suppressing the Th17 immune response. This provides novel ideas for organ protection and targeted drug therapy during the perioperative period.

\section{Acknowledgements}

This study was supported by the Natural Science Foundation of China (grant nos. 81471121 and 3120175), the New Teacher Foundation of China Medical University (XZR20160036), and the Liaoning Natural Fund Project (2015020404).

\section{Disclosure Statement}

No conflict of interests exists.

\section{References}

1 Tang N, Jiang R, Wang X, Wen J, Liu L, Wu J, Zhang C: Insulin resistance plays a potential role in postoperative cognitive dysfunction in patients following cardiac valve surgery. Brain Res 2017;1657:377382.

2 Kok WF, Koerts J, Tucha O, Scheeren TW, Absalom AR: Neuronal damage biomarkers in the identification of patients at risk of long-term postoperative cognitive dysfunction after cardiac surgery. Anaesthesia 2017;72:359-369. 


\section{Cellular Physiology Cell Physiol Biochem 2018;46:1175-1188 \begin{tabular}{l|l} 
and Biochemistry Publishecol 10.1159/000489068 & $\begin{array}{l}\text { (c) } 2018 \text { The Author(s). Published by S. Karger AG, Basel } \\
\text { www.karger.com/cpb }\end{array}$
\end{tabular}}

Chen et al.: Activated A7nachr Improves POCD and Intestinal Injury by Th17 Immune Response During CPB

3 Sedighinejad A, Imantalab V, Mirmansouri A, Mohammadzadeh Jouryabi A, Kanani G, Nassiri Sheikhani N, Haghighi M, Atrkarroushan Z, Biazar G: Effects of Low-dose Selenium on the Inflammatory Response in Coronary Artery Bypass Graft Surgery: A Clinical Trial. Iran Red Crescent Med J 2016;18:e37918.

4 Adamik B, Kubler A, Gozdzik A, Gozdzik W: Prolonged Cardiopulmonary Bypass is a Risk Factor for Intestinal Ischaemic Damage and Endotoxaemia. Heart Lung Circ 2017;26:717-723.

5 Plicner D, Stolinski J, Wasowicz M, Gaweda B, Hymczak H, Kapelak B, Drwila R, Undas A: Preoperative values of inflammatory markers predict clinical outcomes in patients after CABG, regardless of the use of cardiopulmonary bypass. Indian Heart J 2016;68:S10-S15.

-6 Patel N, Minhas JS, Chung EM: Risk Factors Associated with Cognitive Decline after Cardiac Surgery: A Systematic Review. Cardiovasc Psychiatry Neurol 2015;2015:370612.

-7 Yuan S, Zhang X, Bo Y, Li W, Zhang H, Jiang Q: The effects of electroacupuncture treatment on the postoperative cognitive function in aged rats with acute myocardial ischemia-reperfusion. Brain Res 2014;1593:19-29.

8 Mollhoff T, Loick HM, Van Aken H, Schmidt C, Rolf N, Tjan TD, Asfour B, Berendes E: Milrinone modulates endotoxemia, systemic inflammation, and subsequent acute phase response after cardiopulmonary bypass (CPB). Anesthesiology 1999;90:72-80.

-9 Borovikova LV, Ivanova S, Zhang M, Yang H, Botchkina GI, Watkins LR, Wang H, Abumrad N, Eaton JW, Tracey KJ: Vagus nerve stimulation attenuates the systemic inflammatory response to endotoxin. Nature 2000;405:458-462.

10 Costa L, Roth M, Miglino N, Keglowich L, Zhong J, Lardinois D, Tamm M, Borger P: Tiotropium sustains the anti-inflammatory action of olodaterol via the cyclic AMP pathway. Pulm Pharmacol Ther 2014;27:29-37.

-11 Costantini TW, Krzyzaniak M, Cheadle GA, Putnam JG, Hageny AM, Lopez N, Eliceiri BP, Bansal V, Coimbra R: Targeting alpha-7 nicotinic acetylcholine receptor in the enteric nervous system: a cholinergic agonist prevents gut barrier failure after severe burn injury. Am J Pathol 2012;181:478-486.

12 von Boyen GB, Steinkamp M, Reinshagen M, Schafer KH, Adler G, Kirsch J: Proinflammatory cytokines increase glial fibrillary acidic protein expression in enteric glia. Gut 2004;53:222-228.

-13 Esplugues E, Huber S, Gagliani N, Hauser AE, Town T, Wan YY, O’Connor W, Jr., Rongvaux A, Van Rooijen N, Haberman AM, Iwakura Y, Kuchroo VK, Kolls JK, Bluestone JA, Herold KC, Flavell RA: Control of TH17 cells occurs in the small intestine. Nature 2011;475:514-518.

14 Liu ZJ, Yadav PK, Su JL, Wang JS, Fei K: Potential role of Th17 cells in the pathogenesis of inflammatory bowel disease. World J Gastroenterol 2009;15:5784-5788.

15 Liu Z, Han B, Li P, Wang Z, Fan Q: Activation of alpha7nAChR by nicotine reduced the Th17 response in CD4(+)T lymphocytes. Immunol Invest 2014;43:667-674.

16 Cao HJ, Sun YJ, Zhang TZ, Zhou J, Diao YG: Penehyclidine hydrochloride attenuates the cerebral injury in a rat model of cardiopulmonary bypass. Can J Physiol Pharmacol 2013;91:521-527.

17 Liu YH, Wang DX, Li LH, Wu XM, Shan GJ, Su Y, Li J, Yu QJ, Shi CX, Huang YN, Sun W: The effects of cardiopulmonary bypass on the number of cerebral microemboli and the incidence of cognitive dysfunction after coronary artery bypass graft surgery. Anesth Analg 2009;109:1013-1022.

18 Ozturk S, Sacar M, Baltalarli A, Ozturk I: Effect of the type of cardiopulmonary bypass pump flow on postoperative cognitive function in patients undergoing isolated coronary artery surgery. Anatol J Cardiol 2016;16:875-880.

19 Yi SQ, Yang M, Duan KM: Immune-Mediated Metabolic Kynurenine Pathways Are Involved in the Postoperative Cognitive Dysfunction after Cardiopulmonary Bypass. Thorac Cardiovasc Surg 2015;63:618623.

20 Feng J, Liu H, Chen J, Wang J, Liu Z, Ge S: Levosimendan Reduces Lung Injury in a Canine Model of Cardiopulmonary Bypass. Korean Circ J 2016;46:402-407.

-21 Algaze CA, Koth AM, Faberowski LW, Hanley FL, Krawczeski CD, Axelrod DM: Acute Kidney Injury in Patients Undergoing the Extracardiac Fontan Operation With and Without the Use of Cardiopulmonary Bypass. Pediatr Crit Care Med 2017;18:34-43.

-22 Sun YJ, Cao HJ, Jin Q Diao YG, Zhang TZ: Effects of penehyclidine hydrochloride on rat intestinal barrier function during cardiopulmonary bypass. World J Gastroenterol 2011;17:2137-2142.

23 Gahring LC, Rogers SW: Neuronal nicotinic acetylcholine receptor expression and function on nonneuronal cells. AAPS J 2006; 7:E885-894. 


\section{Cellular Physiology Cell Physiol Biochem 2018:46:1175-1188

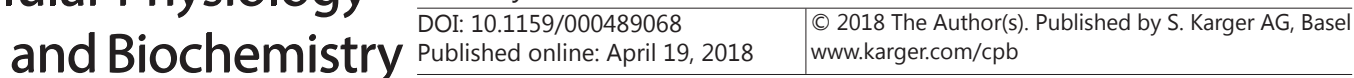

Chen et al.: Activated A7nachr Improves POCD and Intestinal Injury by Th17 Immune Response During CPB

24 Kawashima K, Fujii T: Basic and clinical aspects of non-neuronal acetylcholine: overview of non-neuronal cholinergic systems and their biological significance. J Pharmacol Sci 2008;106:167-173.

25 Pavlov VA, Parrish WR, Rosas-Ballina M, Ochani M, Puerta M, Ochani K, Chavan S, Al-Abed Y, Tracey $\mathrm{KJ}$ : Brain acetylcholinesterase activity controls systemic cytokine levels through the cholinergic antiinflammatory pathway. Brain Behav Immun 2009;23:41-45.

-26 Wang H, Yu M, Ochani M, Amella CA, Tanovic M, Susarla S, Li JH, Wang H, Yang H, Ulloa L, Al-Abed Y, Czura CJ, Tracey KJ: Nicotinic acetylcholine receptor alpha7 subunit is an essential regulator of inflammation. Nature 2003;421:384-388.

-27 de Jonge WJ, van der Zanden EP, The FO, Bijlsma MF, van Westerloo DJ, Bennink RJ, Berthoud HR, Uematsu S, Akira S, van den Wijngaard RM, Boeckxstaens GE: Stimulation of the vagus nerve attenuates macrophage activation by activating the Jak2-STAT3 signaling pathway. Nat Immunol 2005;6:844-851.

28 Lad DP, Varma S, Varma N, Sachdeva MU, Bose P, Malhotra P: Regulatory T-cell and T-helper 17 balance in chronic lymphocytic leukemia progression and autoimmune cytopenias. Leuk Lymphoma 2015;56:24242428.

29 Wing AC, Hygino J, Ferreira TB, Kasahara TM, Barros PO, Sacramento PM, Andrade RM, Camargo S, Rueda F, Alves-Leon SV, Vasconcelos CC, Alvarenga R, Bento CA: Interleukin-17- and interleukin-22-secreting myelin-specific CD4(+) T cells resistant to corticoids are related with active brain lesions in multiple sclerosis patients. Immunology 2016;147:212-220.

-30 Chehimi M, Vidal H, Eljaafari A: Pathogenic Role of IL-17-Producing Immune Cells in Obesity, and Related Inflammatory Diseases. J Clin Med 2017;6:piiE68.

-31 Nadkarni S, Smith J, Sferruzzi-Perri AN, Ledwozyw A, Kishore M, Haas R, Mauro C, Williams DJ, Farsky SH, Marelli-Berg FM, Perretti M: Neutrophils induce proangiogenic T cells with a regulatory phenotype in pregnancy. Proc Natl Acad Sci U S A 2016;113:E8415-E8424. 